\title{
Total diz artroplastisi sonrası ağrı kontrolü ve rehabilitasyon
}

\author{
Pain control and rehabilitation after total knee arthroplasty
}

\author{
Barış Kadıoğlu¹, Budak Akman¹, Şerife Gülçin Gülşen Özkurt
}

\author{
${ }^{1}$ Ataşehir Florence Nightingale Hastanesi, Ortopedi ve Travmatoloji Bölümü, İstanbul, Türkiye \\ ${ }^{2}$ Ataşehir Florence Nightingale hastanesi, Fizik tedavi ve Rehabilitasyon Bölümü, İstanbul, Türkiye
}

\begin{abstract}
Illeri evre diz osteoartritinde konservatif tedaviye yanıt vermeyen olgularda yapılan total diz protezinde oldukça başarılı sonuçlar bildirilmesine rağmen, \%20-30 hastada ameliyat sonrası ağrının devam etmesi, hasta ve doktorda memnuniyetsizliğe yol açmaktadır. Ayrıca hastalar, ağrı yönünden birbirlerinden aldıkları olumsuz geri bildirimler ile diz protezi ameliyatı olmaktan kaçmaktadırlar. Ameliyat sonrası dönemdeki hissedilen ağrı ve bunun yönetimi diz protezi ameliyatlarının başarısını etkileyen önemli faktörlerden biri olmaya devam etmektedir. Güncel literatür ameliyat esnası opioid tüketimini azaltmak için multi-modal ağrı kontrolü yaklaşımı üzerine odaklanmıştır. Multi-modal ağrı kontrolü yaklaşımı, ameliyat esnası yara çevresine uygulanan lokal anestezik maddeler ile sinir bloklarının kombinasyonunu içermektedir. Ameliyat sonrasında iyi kontrol edilmiş ağrı, erken fonksiyonel iyileşme ve hasta memnuniyeti ile doğrudan ilişkilidir. Bu nedenle ameliyat sonrası dönemde ağrıyı azaltmak, erken rehabilitasyona başlamak, bağımsız ambulasyonu sağlamak temel hedefimiz olmalıdır. Bu hedefe ulaşmak için her hasta multi-disipliner yaklaşım içinde ele alınmalı ve multi-modal ağrı kontrolü ile birlikte hastaya özel rehabilitasyon programları uygulanmalıdır.
\end{abstract}

Anahtar sözcükler: total diz protezi; ağıı kontrolü; fizik tedavi; rehabilitasyon

\begin{abstract}
Although quite successful results have been reported in total knee prosthesis performed in patients who do not respond to conservative treatment in advanced stage knee osteoarthritis, the persistence of postoperative pain in 20$30 \%$ of patients causes dissatisfaction in the patients and physicians. In addition, patients are avoiding knee prosthesis surgery due to the negative feedback received from the operated patients in terms of pain. The management of the pain after total knee prosthesis surgery is one of the important factors affecting the success of these surgery. Current literature is focused on the multi-modal pain control to decrease the use of the perioperative opioids. The multi-modal pain control approach involves perioperative combination of nerve blocks and operation site local anaesthetic injections. Successful management of the postoperative pain is directly associated to the early functional healing and the satisfaction of the patient. So, the main goal of the postoperative therapy should be to reduce the pain, to start early rehabilitation and to provide independent ambulation. In order to achieve this goal, each patient should be handled in multidisciplinary approach and provide patient-specific rehabilitation programs with multimodal pain control.
\end{abstract}

Key words: total knee arthroplasty; pain control; physical therapy; rehabilitation
T otal diz protezinde (TDP) hedef, diz ekleminin dengesini ve hareket açıklığını sağlamak, ağrıyı dindirmektir. Ortalama yaşam sürelerinin uzaması, ileri yaş nüfusun artmasıyla birlikte eklem protezlerine ihtiyaç artmakta, fakat ileri yaşlardaki kas ve bağlarda zayıflıklar, ilave hastalıklar nedeniyle uzayan immobilizasyonlar ve dolaşım bozuklukları diz protezinin başarısını düşürebilmektedir. ${ }^{[1,2]}$

Bir yandan ilerleyen teknolojiler, gelişen bilimsel yöntemlerle cerrahi yöntemin başarısı artmakta iken, yaş ve immobilize yaşamın negatif etkisi ile komplikasyonlar ve ağrı şikâyetinin devamı hasta memnuniyetsizliğine yol açabilmektedir. ${ }^{[3]}$

Total diz protezi uygulanan hastaların günlük yaşam aktivitelerine en kısa sürede dönmesi, ağrısız yaşama kavuşması için multidisipliner çalışma önemlidir.

Diz protezi sonrası rehabilitasyonunun amacı; komplikasyonların oluşmasını engellemek ve replasman yapılan ekleme aşırı yüklenme olmaksızın, hastanın mümkün olan en kısa sürede günlük yaşam aktivitelerine dönmesinin sağlanmasıdır.

İletişim / Contact: Doç. Dr. Budak Akman • E-posta / E-mail: drbudakakman@gmail.com

ORCID iD: Barış Kadığlu, 0000-0001-9631-8483 • Budak Akman, 0000-0002-0918-6361 • Şerife Gülçin Gülşen Özkurt, 0000-0002-3352-2636 
Total diz protezi uygulanan hastaların \%20-30'unda ameliyat sonrası dönemde ağrı şikâyeti devam etmekte, bu da beraberinde hasta memnuniyetsizliğini getirmektedir. ${ }^{[4,5]}$ Ameliyat sonrasında, iyi ağrı kontrolü ile hasta memnuniyeti artarken, rehabilitasyon uygulamaları kolaylaşmakta ve hastanede kalış süresi kısalmaktadır. İyi bir ağrı kontrolü ve rehabilitasyon ile en önemli kazanım maksimum hareket açıklığının kazanılması ile artrofibrozis gelişiminin önlenmesi olacaktır.

Ayrıca erken ve başarılı rehabilitasyon ile derin ven trombozu, pulmoner emboli, pnömoni ve üriner retansiyon gibi başka organ komplikasyonları da azalmaktadır. ${ }^{[5]}$

En sık karşılaşılan ağıı nedenleri; enfeksiyon, instabilite, patellofemoral problemler, osteoliz ve protezin gevşemesidir. ${ }^{[3,4]}$

Ağrılı TDP'li hastalarda sistematik bir değerlendirme yapılmalıdır. Cerrahi girişim ile ilgili ağrıya neden olabilecek etkenlerin ayırt edilmesi en önemli konudur. ${ }^{[3]}$

Total diz protezi ameliyatı sonrasında genelde ilk üç aylık süreç içerisinde bir miktar ağrı olabilmektedir. Daha az hasta grubunda ise, üç ay sonrasında da ağrı devam edebilir. ${ }^{[4,6]}$

Ağrının uzun sürmesi ve şiddetli olması eklem hareket açıklığının istenilen düzeye ulaşamamasına ve eklem sertliğine sebep olabilir, gerekiyorsa bu süreçte analjezik ilaç kullanımına düzenli devam edilmelidir. Ağrı kesici kullanırken hasta takibi düzenli yapılmaIı ve ağrıyı oluşturabilecek intrinsik sebepler gözardı edilmemelidir. ${ }^{[7,8]}$ Dizde enfeksiyon gelişme olasılığı özellikle cerrahiyi takip eden ilk bir yıl içinde daha yüksektir. Ayrıca protezde gevşeme, osteoliz ve aşınma da ilk bir yıl içinde ağrı sebepleri içinde öncelikli düşünülmelidir. Bu derlemenin konusu ameliyat sonrasında görülen cerrahiye bağlı ağrı ve bunun kontrolüdür. Eklem kapsülünde bulunan serbest sinir uçlarının, sinovyal dokunun ve anterior yağ yastığının tahrişini içeren çeşitli sebepler ameliyat sonrası diz ağrısını oluşturabilmektedir. ${ }^{[9-11]}$

Ameliyat öncesinde korku düzeyi yüksek olan hastaların ameliyat sonrasında daha fazla ağrı yaşadıkları belirlenmiştir. Cerrahi girişim planlanan hastaların cerrahi korku düzeyleri ve nedenleri belirlenerek korkuyu azaltacak hasta eğitimlerinin bu doğrultuda kapsamlı verilmesi önerilmektedir. ${ }^{[6]}$

Total diz protezini takiben uygulanan analjezi genellikle multimodal olup, hasta kontrollü analjezi (patientcontrolled analgesia), periferik sinir bloğu, epidural analjezi, eklem veya sinovya içi opioid veya lokal anestezikler ile oral analjezik kullanımını içermektedir. Multimodal analjezi ağrı yolunun farklı bölgelerine etki eden analjezik ajanların birlikte kullanımı ile sağlanmaktadır. ${ }^{[7,9]}$
Diz protezinde multimodal analjezi ile ilgili çok sayıda çalışma vardır, ancak sonuçlar çelişkilidir. Belli bir algoritma oluşmamıştır. Tam ve uzun süreli ağrı kesmeyi sağlamak için analjeziye ameliyatı uygulamadan önceki dönemde başlanması uygundur ve TDP sonrası ağrı giderimi ve fonksiyonel iyileşmeyi sağlamanın yolu, ameliyat esnasında yeterli anestezi verilmesinden geçer.[11] Ameliyat sonrası ağrıyı hafifletmek için çeşitli yeni ilaçlar ve yeni teknikler uygulanmaktadır. Ağrı sebeplerinin farklı olması dışında, ağrı algılamadaki bireysel farklılıklar da ağrı yönetimini standart hale getirmeyi zorlaştırır. ${ }^{[10]}$

Total diz protezinde (TDP) ameliyat esnası analjezinin yönetimi için başlıca modaliteler şunlardır:

1- Önleyici analjezi: Bu uygulamalar hastanın ağrısı başlamadan kontrol altına almayı ve hastadaki hoş olmayan ağrı izlenimlerini bloke ederek daha rahat bir ameliyat sonrası dönem geçirmeyi hedeflemektedir. Antinosiseptif bir tedavi olan önleyici analjezi, ameliyat sırasında oluşan kesi kaynaklı ve cerrahi travmanın neden olduğu ağı duyarlılığının önlenebilmesi için ameliyattan önce başlatılan tedavidir. Önleyici analjeziden ameliyat öncesi yapılması ile birlikte erken ameliyat sonrası dönemde de yararlanılabilir. ${ }^{[12]}$ Ağrı hissini engellemek için literatürde yer alan çeşitli yaklaşımlar aşağıda belirtilmiştir.

- Nonsteroid anti-inflamatuvar ilaçlar (NSAii) (oral veya parenteral): Özellikle Cox- 2 inhibitörlerinin bir gece önce başlanması ameliyat sonrası erken ağrı kontrolünde yarar sağlamaktadır.

- Uzun etkili oral ve intravenöz (IV) opioidler: Uzun etkili opioidler (oxycodone) standart opiodlere göre daha etkili olduğu ve böylelikle daha erken rehabilitasyona başlanabildiği belirtilmesine karşın ciddi yan etkilere sahip olduğundan ilk tercih olmamalıdır.

- Sistemik antiepileptikler (gama-amino bütirik asit "GABA" analogları): Hem pregabalin hem de gabapentin, ameliyat esnası ağrı yoğunluğunu, opioid tüketimini ve opioidle ilişkili yan etkileri azaltmada etkilidir ve çok az yan etki üretir. ${ }^{[10]}$

2- Lokal infiltrasyonlar: Ameliyat sırasında bazı ilaçların yara boyunca nüfuz etmesini içeren basit ve etkili bir analjezik tekniktir. Analjezinin etki süresi, lokal anesteziklerin ameliyat sonrası uygulanması için cerrahi alana bir kateterin hassas bir şekilde yerleştirilmesiyle uzatılabilir. Hem eklem içi hem de eklem dışı enjeksiyon için en çok kullanılan ilaçlar morfin, steroid, klonidin, efenefrin, ketorolak, ropivasin ve bupivakaindir. ${ }^{[12,13]}$ 
3- Lokal anestezi ile intratekal morfin: Ameliyat sonrası ağrıyı hafifletmek için intratekal (iT) morfin ile desteklenen lokal anestezi, ameliyat sonrası iyi bir analjezi sağlar. Bu kombinasyon aynı zamanda ilk 24 saat için parenteral opioid koruyucu etkiye neden olur. ${ }^{[14]}$ Ancak, birçok avantaja rağmen, bu yaklaşım, artan idrar retansiyonu sıklığı, bulantı-kusma ve kaşıntıya neden olabilmektedir. Düşük doz intratekal morfinin (yaklaşık 100 mikrogram) çok etkili olduğunu ve femoral sinir bloğundan daha güvenli olabileceği öne sürülmektedir. ${ }^{[15]}$

4- Epidural analjezi: Epidural analjezi, diz protezi ameliyatlarından sonra ameliyat sonrası analjezi için kanıtlanmış ve en başarılı, en yaygın kullanılan tekniklerden biridir. Bazı çalışmalarda TDP uygulanan hastalarda ağrı kontrolü ve daha hızlı diz rehabilitasyonu amacıyla kontrollü epidural analjezi tekniğinin, intravenöz analjeziye göre üstün olduğu bildirilmektedir. ${ }^{[14]}$ Epidural analjezinin bazı yan etkileri olup bunlar, istenmeyen motor blokajı, bağırsak ve mesane aktivitesinde disfonksiyon ve hemodinamik istikrarsızlıktır. ${ }^{[15]}$

5- Bölgesel sinir blokları: Total diz protezinde bölgesel analjezi, epidural analjeziye göre geniş bir kabul görmektedir. Bu yaklaşım, daha az yan etkiye neden olur. Bölgesel sinir bloğu alt ekstremite innervasyonunu sağlayan (siyatik-femoral-obturator) bir veya daha fazla periferik sinirin bloke edilmesinden oluşmaktadır. Bununla birlikte, bu ana sinirlerin blokajları, kaslarda güçsüzlük ve kontrolde azalmaya neden olarak erken dönem fonksiyonel aktivitelerde ve mobilizasyonda gecikmeye neden olabilmektedir. Tüm bu faktörler hastanın erken fonksiyonel iyileşmesini etkileyebilir. ${ }^{[7,11,15]}$

a- Femoral sinir bloğu: Femoral sinir blokajı diz protezini takiben analjezi için sık kullanılan bir yöntemdir. Ağrıyı kesmede etkili olmasına rağmen sık olarak cerrahi sonrasındaki günde kuadriseps zayıflığına bağı mobilizasyonda güçlük ve düşme riskinde artış görülebilmektedir. Yapılmış bir çalışmada, diz eklemi arka kapsülüne analjezik infiltrasyonu ile femoral sinir bloğu ve periartiküler infiltrasyon analjezisi uygulanan iki grupta narkotik analjezik kullanımının azaldığı ve femoral sinir bloğu uygulanan grupta analjezik etkinliğinin bir gün daha uzun sürdüğü belirtilmiştir. Ancak diz eklemi arka kapsülüne analjezik infiltrasyonu uygulamadan, tek başına femoral sinir bloğu arka kapsülde yeterli analjeziyi sağlayamaz ve diz arkası bölgede ağrı devam edebilir. ${ }^{[12,15]}$
Kombine siyatik ve femoral sinir bloğu ile tek başına femoral sinir bloğuna göre daha üstün bir analjezi sağlanmaktadır. Ancak bu kombine blok hamstring ve kuadriseps kaslarında motor bloğa neden olarak, mobilizasyon sırasında hastaların düşme riskini artırmaktadır. ${ }^{[15]}$

Diz eklemi arka kapsülüne uygulanan infiltrasyon, uygulama kolaylığı ve potansiyel olarak düşük morbiditeye sahip olmasından dolayı siyatik bloğa göre daha üstündür ve aralarında ameliyat sonrası ağıı kontrolü açısından istatistiksel bir fark yoktur. ${ }^{[15]}$

Kovalak ve ark.'nın ${ }^{[12]}$ çalışmasında, Carli ve ark. ${ }^{[13]}$ tarafından yapılan çalışmadan farklı olarak arka kapsüldeki ağrıyı elimine ederek, grupları benzer kılmak için her iki grupta arka kapsüle analjezik infiltrasyonu uygulanmış. Bu şekilde, benzer kılınan gruplar arasında femoral katater uygulanan hastaların, ameliyat sonrası istirahattaki ağrı kontrolünün daha iyi olduğu görülmüştür. Ayrıca bu çalışmada egzersizden hemen sonra oluşan ağrı da femoral sinir bloğu yapılan grupta, periartiküler infiltrasyon uygulanan gruba göre anlamlı derecede az bulunmuş. Sonuç olarak, femoral sinir bloğu (FSB), diz eklemi arka kapsülüne infiltrasyon analjezisi ile uygulandığı takdirde düşük yan etki profili ile ameliyat sonrası daha yüksek hasta konforu ve daha fazla hareket açıklığı sağlayan etkili ve güvenilir bir analjezi yöntemi olarak düşünülebilir. FSB'nin en büyük dezavantajının ise kuadriseps zayıflığı ve buna bağlı mobilizasyon sırasında düşme riski olduğu akıldan çıkarılmamalıdır.

b- Adduktor kanal bloğu (AKB): Ultrason eşliğinde bir teknik olan adduktor kanal bloğu (AKB), diz cerrahisi sonrası ameliyat sonrası analjezi için en önemli ve en basit duyusal sinir bloğudur. Adduktor kanal birden fazla farklı sinir ve genellikle duyusal lifler içerdiğinden motor blokaj daha az olmaktadır. Böylelikle AKB, femoral sinir kateteri ile karşılaştırıldığında ağrı yönetiminde daha başarılıdır. Adduktor kanal bloğu kuadriseps kas gücünü koruyarak iyi bir analjezi sağlar bu da rehabilitasyonun başarısını artırarak, iyileşmeyi hızlandırır. ${ }^{[14]}$

c- I-Pack bloğu: Popliteal arter ve posterior diz kapsülü arasındaki boşlukta yapılan işlemdir, adduktor kanal bloğu ile birleştirildiğinde analjezik etki oluştuğu öne sürülmüştür. ${ }^{[7]}$ Arka diz kapsülünün analjezisi hedeftir. Ana sinirleri koruyarak tibial ve peroneal sinirlerin terminal eklem dallarını bloke ederek yardımcı olur. 
d- Sub-sartorial kompartman bloğu: Bu işlem diz proksimalindeki adduktor hiatusa distal olarak sartorius kasının altına ultrason kılavuzluğunda lokal anestezik (LA) enjeksiyonudur. Bu yaklaşım, LA'yı safen sinir çevresinde biriktirmeyi amaçlamaktadır. Bu sinir, geniküler arterin safen dalına bitişiktir. Bu yaklaşımda blok duyusal blok görevi görür ve herhangi bir motor felce neden olmaz. ${ }^{[11]}$

e- Obturator sinir bloğu: TDP ağrısında obturator sinirin göreceli katkısı tartışmalıdır. Bu yaklaşım öncelikle deriyi ve uyluğun medial yönü üzerindeki adduktor kasını etkiler. Arka dallar popliteal damarları takip eder ve popliteal pleksus ile birleşir ve TDP hastalarında posterior diz ağrısının azaltılmasında rol oynayabilir. ${ }^{[4]}$ Ancak uygulaması basit olmadığından yaygın kullanım alanı bulmamıştır.

6- Kombinasyonlar-multimodal analjezi: Total diz protezi sonrası multimodal analjezi, ameliyat öncesiameliyat sırasında-ameliyat sonrasında farklı tekniklerin uygulanması ile elde edilir (Tablo 1). Analjezik etkiyi artırmak ve ilaçların yan etkilerini azaltmak amacıyla yapılan kapsamlı bir yaklaşımdır. En güncel Multimodal analjezi yaklaşımında ameliyat öncesi Cox-2 inhibitörlerinin başlanması, ameliyat içinde periartiküler enjeksiyonlar ve periferik sinir bloğu, anestezi tekniği olarak da spinal anestezinin tercih edilmesi gerektiği vurgulanmıştır. ${ }^{77,15]}$

Sonuç olarak; total diz artroplastisini takiben uygulanan ağrı yönetiminde, multimodal ve önleyici analjezinin doğru bir şekilde birleştirilmesi, bölgesel sinir

Tablo 1. Multimodal ağrı yönetiminde seçenekler ${ }^{[7]}$

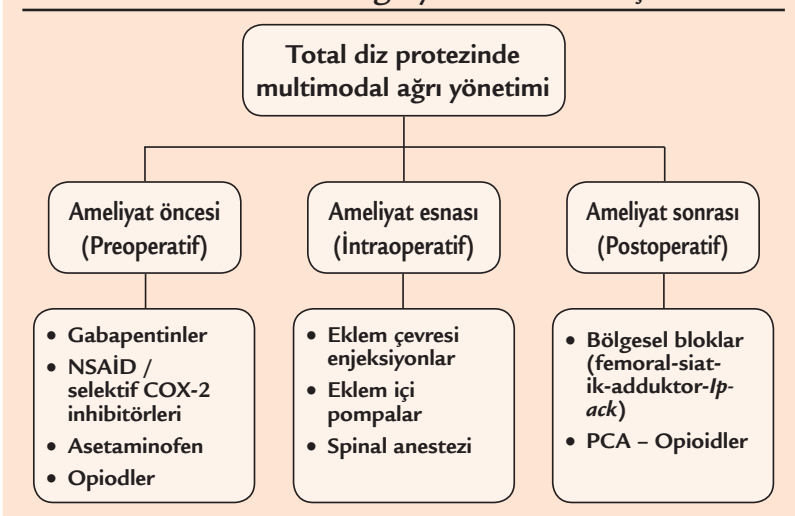

NSAID, non-steroidal anti-inflamatuvar ilaçlar; COX, siklooksijenaz; Ipack, popliteal arter ile dizin posterior kapsülü arası alan; PCA, hasta kontrollü ağrı pompası bloklarının uygun olanının seçilmesi ve ameliyat sonrası erken fizik tedavi-rehabilitasyon temel bileşenlerdir. Bu yaklaşım hem fonksiyonel iyileşmeyi hızlandırı hem de geleneksel opioid bazlı analjezinin yan etkilerini en aza indirir, hasta memnuniyetini artırır ve toplam hastanede kalış süresini azaltır.

Total diz protezini takiben uzun süreli ağrı ve ağrının giderilememesi rehabilitasyona uyumu bozmaktadır. Bunun sonucunda artrofibrozis görülebilmektedir. TDP sonrası hareket kabiliyetinin artması, fonksiyonel iyileşmenin yanı sıra ağrının azalmasında da çok önemlidir. Yapılan çalışmalar bazı hastalarda hareket korkusu (kinezyofobi), proteze zarar verme ve ağrının artması gibi çekincelerin varlığını göstermiştir. Cerrahi öncesi aktivite algıları eğitimi ile hareket korkusu azaltılabilmektedir. ${ }^{[16]}$

Diz replasmanı geçirmiş bireylere verilen egzersiz eğitiminin yaşam kalitesi, hareket korkusu, ağrı ve eklem sertliği üzerine olan etkisini incelemek amacıyla yapılan çalışmada, en az altı ay önce TDP geçiren hastalara, sekiz hafta süreyle özel egzersiz programı düzenlenerek takibe alındığında ve elde edilen verilere bakıldığında; egzersiz öncesi ve sonrası ağrıda, hareket korkusu ve eklem sertliğinde azalma olduğu, fiziksel fonksiyon, enerji ve ruh sağlığı parametresinde ise artma olduğu belirtilmiştir. ${ }^{[17]}$

Total diz protezinde cerrahinin başarısını artırmak, komplikasyonları engellemek ve hasta memnuniyetini artırmak amacıyla rehabilitasyon cerrahi öncesi dönemde başlamalıdır.

Total diz protezi uygulanma kararı verilen hastanın, ameliyat öncesi günlük yaşam aktivitelerine katılımı, kas ve yumuşak doku, eklem hareket ölçümleri, postür ve yürüme analizi değerlendirmeleri yapılmalı, ek hastalıkları göz önünde tutulmalıdır. ${ }^{[17,18]}$

Diz cerrahisi sonrasında rehabilitasyon programı ne kadar erken başlanırsa alınacak sonuç o kadar başarılı olacaktır. Rehabilitasyon programı sırasında normale yakın eklem hareket açıklığı, yürüme paterni ve kadans kazanılmadıkça hastanın yardımsız ve tam ağılıkla basmasına izin verilmemelidir. Ekstansör ya da fleksör mekanizmada refleks inhibisyon gelişimi erkenden tanınmalı ve uygun fizik tedavi modaliteleriyle rehabilitasyon uygulanmalıdır. ${ }^{[2,19-21]}$

Total diz protezi uygulanması öncesi ortopedi ve travmatoloji doktorunun hastayı değerlendirmesi ve rehabilitasyon programıyla ilgili hastayı bilgilendirmesi için fizik tedavi ve rehabilitasyon doktoru ile işbirliği halinde olması önerilmektedir. Ortopedi ve travmatoloji uzmanı, fizik tedavi ve rehabilitasyon uzmanı, fizyoterapist ve hasta arasındaki iyi bir iletişim rehabilitasyon programının başarısı ve dolayısıyla uygulanan cerrahi işlemin başarısı için önemlidir. ${ }^{[20]}$ 


\section{AMELIYAT ÖNCESI DEĞERLENDIRME VE PREHABILITASYON}

Diz protezi işlemi, elektif bir cerrahi girişim olduğundan ameliyat öncesi (preoperatif) değerlendirme için genelde yeterli süre bulunmaktadır. Ameliyat öncesi değerlendirmede; öncelikle ameliyat endikasyonu, planlanan cerrahi teknik ve protez cinsi hakkında bilgi alınır. Sistemik hastalık, kullanılan ilaçlar sorgulanır. Hasta diyabetik ya da steroid kullanıyor ise yara iyileşmesi gecikeceğinden ameliyat sonrası (postoperatif) aktif ve pasif eklem hareket açıklığı (EHA) egzersizlerinde tedrici gidilebilir. Kardiyovasküler hastalığı, solunum problemi ve periferik dolaşım bozukluğu olanlar ameliyat sonrası egzersiz toleransı açısından iyi değerlendirilmeli ve ameliyat sonrası derin ven trombozu ve emboli riski düşünülerek erken mobilizasyona başlanması hedeflenmelidir. Eklem patolojisi enflamatuvar bir hastalığa bağlı ise cerrahi sonrası enflamasyon aktive olabileceği için fizik tedavi programı düzenlenirken dikkate alınmalıdır. Doku iyileşmesini hızlandıran laser ve ultrason gibi derin ısıtıcılar enflamasyonu artırabilmektedirler. ${ }^{[22-24]}$ Son olarak ameliyat öncesi diz çevresi ve özellikle kuadriseps kas gücü değerlendirilmelidir. Güncel olarak diz protezi öncesi fizik tedavi müdahaleleri kas güçlendirme, aerobik kondisyon ve eğitim üzerine odaklıdır. Bu müdahaleler için 'prehabilitasyon' ifadesi kullanılmaktadır. ${ }^{[20,21]}$

Swank ve ark., yaptıkları bir çalışmada ilaç tedavisine dirençli şiddetli diz osteoartriti (OA) ve eklem ağrısı olan hastalarda TDP öncesi 4-8 hafta süreyle uygulanan olağan bakım ve egzersizlerden (direnç, fleksibilite ve step) oluşan prehabilitasyon programının fonksiyonel performans ve kas kuvveti üzerine olumlu gelişme sağladığını kaydetmişlerdir. ${ }^{[1]}$ Jones ve ark., ameliyat öncesi dönemde eğitim programı uygulamasının hastanede yatış süresini azaltan etkili bir yöntem olduğu hipotezini desteklemişlerdir. Bu program cerrahi öncesi 4 hafta içinde grup formatı şeklinde uygulanmış, cerrahi öncesi hazırlık, diz protezi prosedürleri, cerrahinin riskleri ve yararları, cerrahiden sonraki ilk 24 saat içinde yürümeye yardımcı cihazlarla güvenli ve bağımsız mobilizasyon ve egzersiz programlarını içermiştir. ${ }^{[19]}$ Lei ve ark., operasyondan dört hafta önce, $40 \mathrm{dk} /$ gün süreyle ameliyat öncesi ev rehabilitasyon eğitim programına katılan hastalarda hastanede yatış süresinin azaldığını ve maliyet tasarrufunun arttığını belirtmişlerdir. Ev rehabilitasyon programının içeriğini kas kuvveti çalışmaları (düz bacak kaldırma, ayak pompalama ve dirençli kalça abduksiyonu egzersizleri), ameliyat sonrası dönemde güvenli transfer teknikleri, kanadyen veya koltuk değneği kullanımı ve düşmeden korunma bilgilendirmesi olarak tanımlamışlar, bu programı TDP planlanan $O A^{\prime} l ı$ hastalarda ameliyat öncesi süreçte rutin bir protokol olarak tavsiye etmişlerdir. ${ }^{[23]}$ Jahic ve ark., total diz protezi öncesi rehabilitasyon programı uygulanan hastalarda ameliyat sonrası ve 6 . aya kadar eklem hareket açıklığı (EHA) ve fonksiyonel iyileşmede belirgin fark bildirmişlerdir. Altıncı ay sonrası ve 12 . ayda ise diz EHA'da ameliyat öncesi egzersiz uygulanan grupta üstünlük mevcutken, fonksiyonel durumda ameliyat öncesi rehabilitasyon uygulanan ve uygulanmayan gruplar arasında fark belirtilmemiştir. ${ }^{[21]}$

\section{AMELIYAT SONRASI REHABILITASYON}

Total diz protezi rehabilitasyonunda hangi protokolün kullanılması ile ilgili kesin bir fikir birliği oluşmamıştır. Ancak klasik sayılabilecek ve yaygın kullanılan rehabilitasyon programları mevcuttur.

Akarcalı ve ark., total diz artroplastisini takiben hızlandırılmış sürekli pasif hareket $(\mathrm{SPH})$ protokolü ve aktif fizyoterapi uygulaması ile erken fonksiyonellik sağlandığını, cerrahi sonrası komplikasyonların ve hastanede yatış süresinin azaldığını bildirmişlerdir. ${ }^{[22]}$ SPH'nin eklem hareket açıklığının daha hızlı kazanılmasını sağladığına, venöz tromboemboli, pulmoner emboli ve ağrıyı azalttığına dair veriler bulunmaktadır. SPH kullanımı ile diz fleksiyonunun $90^{\circ}$ 'ye kısa sürede ulaştığı belirtilirken, yara yerinde komplikasyon insidansının arttığını belirten çalışmalar da vardır. TDP uygulanan dizin $40^{\circ}$ 'den fazla fleksiyona gelmesi ile insizyon yerindeki cildin transkutanöz geriliminin önemli ölçüde azaldığı gösterilmiştir. Bu nedenle hızlandırılmış rehabilitasyon protokolleri de dâhil olmak üzere $\mathrm{SPH}$ ile ilk üç gün en fazla $40^{\circ}$ sınırında fleksiyon yapılması önerilmiştir. ${ }^{[22]}$

Lei ve ark., TDP geçiren hastalarda erken ambulasyonun önemini araştırmışlar. ${ }^{[23]}$ Bu çalışmada dinamik ağrı seviyesi, diz fleksiyon hareket açıklığı (Range of Motion, ROM), 12 maddeli fonksiyonel değerlendirme (SF-12) sonuçları, tromboembolik olay insidansı gibi sonuç ölçümleri ve diğer komplikasyonlar, hastanede yatış süresi, toplam hastanede kalış maliyetleri değerlendirilmiştir. TDP'den sonraki 24 saat içinde erken ambulasyon, diz eklem hareket açıklı̆ı ı ve fonksiyonlarının daha hızlı iyileşmesine yol açarken, daha düşük derin ven trombozu ve pulmoner enfeksiyon insidansı ile ilişkili bulunduğu bildirilmiştir. Hastanede yatış süresi ve hastanede kalma maliyetleri de erken ambule grupta daha düşük tespit edilmiştir. ${ }^{[23]}$

Osteoartrit tanısıyla TDP uygulanan hastalarda rehabilitasyona başlamanın etkilerinin değerlendirildiği randomize kontrollü bir çalışmada erken rehabilitasyon başlanan grupta hastanede yatış süresinin ve ağrının azalmasının, EHA, kuadriseps ve hamstring 
kas kuvvetlerinin, yürüme, denge ve günlük yaşam aktivitelerindeki bağımsızlık skorlarının artmasının diğer gruba oranla daha fazla olduğu görülmüştür. ${ }^{[24]}$

Erken ameliyat sonrası dönemde mobiliteyi, gücü ve fleksibiliteyi düzeltmek, ağrıyı azaltmak, derin ven trombozu ve diğer komplikasyonların oluşmasını önlemek ana hedeflerdir. Ayrıca EHA'yı artırmak, yük aktarma tedbirleri, uygun yardımcı cihazla bağımsız ambulasyon, hasta ve ailenin eğitimi ve evde gerekli düzenlemeleri yapmak diğer hedeflerdir. ${ }^{[21]}$

Total diz protezi sonrası klasik rehabilitasyon hedefleri ve protokolü Tablo 2'de ve 3'te özetlenmiştir.

Uygulanan ameliyat tekniklerine bağlı olarak bazı konularda değişiklikler yapılabilir. Bunlardan bir tanesi, cerrahi sırasında tibial tüberkül osteotomisi veya kuadriseps tendon kesisi yapılanlarda 6-8 hafta yeterli iyileşme olduktan sonra düz bacak kaldırma egzersizine başlamak gerekir. Patella mobilizasyon egzersizleri ise fleksibilite amaçlı yapılabilir. Diğer bir konuda protezin çimentolu veya çimentosuz uygulanmasına göre mobilizasyonun değiştirilmesidir. Çimentolu diz protezinden sonra hasta cerrahi sonrası 1. günden itibaren koltuk değneği ile tam yük vererek yürütülebilir. Ancak çimentosuz biyolojik tespit yapılan olgularda 6 . haftaya kadar kısmi yük, 6 . haftadan sonra tam yük ile mobilize edilmelidir. ${ }^{[20]}$

Total diz protezini takiben uygulanan rehabilitasyon programı cerrahi öncesi değerlendirme, bireysel özellikler, cerrahi sonrası durum ve komplikasyonlara göre farklılık gösterse de klasik rehabilitasyon protokolleri mutlaka baz alınmalıdır. TDP sonrası uygulanan klasik fizik tedavi ve rehabilitasyon programına propriyosepsiyon ve denge eğitimlerinin ilave

Tablo 2. Total diz artroplastisini takiben rehabilitasyonun hedefleri ${ }^{[18,25]}$

\begin{tabular}{|c|c|c|c|}
\hline FAZ 1 (1.-10. gün) & FAZ 2 (2.-6. hafta) & FAZ 3 (7.-12. hafta) & FAZ 4 (14.-26. hafta) \\
\hline Aktif kuadriseps kasılması & EHA'yı artırmak & $\mathrm{EHA}>115^{\circ}$ & $\begin{array}{l}\text { Seçilmiş hastalarda eski yaptıkları } \\
\text { spora dönüş }\end{array}$ \\
\hline $\begin{array}{l}\text { Güvenli ve bağımsız } \\
\text { mobilizasyon }\end{array}$ & Kas gücünü artırmak & Kas gücünü artırmak & Kas gücünü artırmak \\
\hline Pasif $0^{\circ}$ diz ekstansiyonu & Şişlik ve enflamasyonu gidermek & $\begin{array}{l}\text { Bacağın eksantrik ve konsantrik } \\
\text { kontrolünü sağlamak }\end{array}$ & Normal yaşama dönüş \\
\hline \multirow[t]{2}{*}{$90^{\circ}$ diz fleksiyonu } & Fonksiyonel aktivitelere dönüş & Kardiyovasküler fitness & \\
\hline & $\begin{array}{l}\text { Genel sağlık durumunu } \\
\text { iyileştirmek }\end{array}$ & Fonksiyonel aktivite performansı & \\
\hline
\end{tabular}

EHA, eklem hareket açıklığı.

Tablo 3. Total diz protezi sonrası klasik rehabilitasyon protokolü[18,25]

Cerrahi sonrası 1.-2. gün (FAZ 1)

Cerrahi sonrası 4.-10. gün (FAZ 1)

Cerrahi sonrası 2.-6. hafta (FAZ 2)

Cerrahi sonrası 7.-12. hafta (FAZ 3)

Cerrahi sonrası 14.-26. hafta (FAZ 4)

Çimentolu protez

Çimentosuz protez
$\mathrm{SPH}\left(0^{\circ}-40^{\circ}\right)$, ayak pompa egzersizleri, izometrik kuadriseps egzersizleri, pasif diz ekstansiyonu, düz bacak kaldırma, kısmi/tam ağılıkla ambulasyon, soğuk uygulama

Ek olarak: $\mathrm{SPH}\left(0^{\circ}-90^{\circ}\right)$, pasif diz ekstansiyonunda germe, aktif/yardımlı kuadriseps egzersizleri, bacak ve kalça kaslarına izometrik-izotonik egzersiz, $90^{\circ}-0^{\circ}$ diz ekstansiyonu

Ek olarak: Öne ve yana merdiven çıkma, öne hamle

Ek olarak: Progresif yürüme programı, fonksiyonel aktivitelere dönüş, hamle, çömelme, merdiven çıkma, eksantrik, konsantrik diz kontrolünü sağlama

Kuadriseps izometrik, düz bacak kaldırma, kalça abduksiyonu- adduksiyonu, çömelme, lateral merdiven çıkma, $90^{\circ}-0^{\circ}$ diz ekstansiyonu, bisiklet, germe (fleksiyonda $105^{\circ}$, ekstansiyonda $0^{\circ}$ ), yüzme, bisiklet, tenise başlama

Cerrahi sonrası 1. günden itibaren yürüteç ile tam yük aktarma, baston en geç 6 . haftada bırakılabilir

Altıncı haftaya kadar kısmi yük, 6. haftadan sonra koltuk değneği ile tolere edilebildiği kadar yük vererek ambulasyon sağlama

$\mathrm{SPH}$, sürekli pasif hareket. 
edilmesinin hastaların denge fonksiyonlarını artıracağı ve düşme risklerini azaltabileceği bildirilmiştir.[1,2,24] Ayrıca standart rehabilitasyon ile birlikte kullanılan nöromusküler elektrik stimülasyon (NMES), ultrasound (US), hidroterapi, transkutanöz elektrik stimülasyonu (TENS) gibi tekniklerin tedaviye eklenmesi ile daha iyi ve daha hızlı sonuç elde edildiği gösterilmiştir. Bu seçeneklerde hasta bazında değerlendirilerek kullanılmaktadır. ${ }^{[24,25]}$

Nöromusküler elektrik stimülasyonu (NMES), bir kas kasılmasını sağlamak için nöro musküler bileşkeye ve çevreleyen kas liflerine elektrik akımının uygulanmasıdır. NMES; motor nöronun dallarına transkutan akım uygulayarak kas kasılmasına neden olur, kas üzerindeki yükü artırarak kas gücünü artırır. TDP rehabilitasyonunda özellikle kuadriseps kasının kuvvetini ve fonksiyonel performansı artırmaya yönelik olarak NMES ameliyattan önce ve sonra yaygın olarak kullanılmaktadır. Son yıllarda NMES'nin ev kullanımına uygun modelleri geliştirilmiştir ve hastaya eğitim vererek, hasta tarafından ev kullanımı da önerilmektedir. TDA uygulanan hastalarda yara iyileşmesi tamamlandıktan sonra, kontrendike durum yok ise hidroterapi programı da öneriler arasındadır. Hidroterapinin TDP sonrası ağrı, dayanıklılık ve fonksiyon bozukluğunu azaltmada etkin olduğu gösterilmiştir. ${ }^{25,26]}$ Total diz artroplastisi rehabilitasyonunda, fizik tedavi modalitelerinden transkutanöz elektrik stimülasyonu (TENS) ağrıyı azaltır, ultrason tedavisinde ses dalgalarının mikromasaj etkisi ile patolojik dokunun dolaşımı artar ve ağrı azalır. Son dönemlerde cryo-ultrason gibi cihazlar soğuk ve ultrasonun etkilerini birleştirerek tedavi etkinliğini artırmıştır. Ödem sorunu olan kişilerde ise konnektif doku masajları ve kompresyon cihazı iyileşmeyi sağlamada kullanılabilecek etkin yöntemlerdendir. ${ }^{[20,25]}$

Taburculuk sonrası uygulanan fizyoterapi ve fonksiyonel egzersizleri içeren ev veya grup programları hastanın fonksiyonelliğini geliştirmek konusunda önemini korumaktadır. ${ }^{[2]}$

Telerehabilitasyon, bilgi ve telekomünikasyon teknolojilerini kullanarak rehabilitasyon hizmetlerini uzaktan sağlar. Telerehabilitasyon yöntemlerinden biri, terapist ile hasta arasında gerçek zamanlı görsel-işitsel etkileşime izin veren klinisyen kontrollü Pan, Tilt, Zoom (PTZ) kamera ve yazılımı içerir. ${ }^{[27]}$

Başka bir yöntem ise sanal egzersiz rehabilitasyon asistanı (VERA)'dır. ${ }^{[28]}$ Bu sistem, fizik tedavi protokollerinin hastalara evde bir ekrandaki animasyonlu bir görüntü aracılığıyla ulaştırılmasına izin verir. VERA, gerçek zamanlı hareketleri algılamak için üç boyutlu kameralar kullanır ve hastaların programdan tam olarak yararlanmaları için gerçek zamanlı geri bildirim sağlamasına olanak tanır. Uzaktan rehabilitasyon sağlamak için tablet uygulamaları da geliştirilmiştir. Terapistler tarafindan 23 videonun oluşturulduğu ve yüklendiği bir iPod touch uygulaması olan CaptureProof fizik tedavi uzmanı ve fizyoterapistler koordine olarak, hasta videoları aracılığıla ilerlemeyi izler ve gerektiğinde geri bildirim sağlar. Diğer web tabanlı platformlar, hastalara ameliyattan sonraki süreye göre gerekli egzersizlerin açıklamaları, resimleri ve videolarını içeren e-postalar gönderebilmektedir. ${ }^{[28]}$

Total diz protezi uygulanan hastalarda birkaç yıl sonra, bazen daha da geç gelişen kas gücünde azalma, fleksibilitede azalma ve yürüme bozuklukları görülebileceğinden uzun süreli takip yapılmalıdır. ${ }^{[2,8]}$

\section{SONUÇ}

Total diz protezine aday olan kişiler, sistemik olarak değerlendirilmelidirler. Ameliyat öncesinde fonksiyonel iyileşmeyi etkileyebilecek durumları, hastalıkları, hatta psikolojik problemleri erkenden tanımlamak ve gerekli önlemleri almak önemlidir. TDP'yi takiben hedef; yaşam kalitesini artırmak ve günlük yaşam aktivitelerinde fonksiyonel bağımsızlığı kazandırmak olduğu için, her hasta multidisipliner yaklaşım içinde değerlendirilmeli ve ameliyatın oluşturacağı ağrı hissi etkili bir biçimde önlenerek kişinin erken dönemde rehabilitasyona uyumu sağlanmalıdır.

\section{KAYNAKLAR}

1. Swank AM, Kachelman JB, Bibeau W, Quesada PM, Nyland J, Malkani A, Topp RV. Prehabilitation Before Total Knee Arthroplasty Increases Strength and Function in Older Adults with Severe Osteoarthritis. J Strength Cond Res 2011;25(2):318-25. Crossref

2. Bryan S, Goldsmith LJ, Davis JC, Hejazi S, MacDonald V, McAllister, Randall E, Suryaprakash N, Wu AD, Sawatzky R. Revisiting patient satisfaction following total knee arthroplasty: a longitudinal observational study. BMC Musculoskelet Disord 2018;19(1):423. Crossref

3. Özkan i. Ağrılı total diz protezinde değerlendirme ve yönetim [Assessment and management of painful total knee prosthesis]. Totbid Derg 2019;18:151-5. https://doi. org/10.14292/totbid.dergisi.2019.17

4. Lee YS. Comprehensive Analysis of Pain Management after Total Knee Arthroplasty. Knee Surg Relat Res 2017;29(2):806. Crossref

5. Singh JA, Lewallen DG. Predictors of use of pain medications for persistent knee pain after primary Total Knee Arthroplasty: a cohort study using an institutional joint registry. Arthritis Res Ther 2012;14(6):R248. Crossref

6. Mete Z, Avcı Işık, Korku Düzeyleri ile Ameliyat Sonrası Ağrı Düzeyleri Arasındaki illişkinin Belirlenmesi. Turkiye Klinikleri J Nurs Sci 2020;12(3):337-47. Crossref 
7. Summers S, Mohile N, McNamara C, Osman B, Gebhard R, Hernandez VH. Analgesia in total knee arthroplasty Current Concept Review. J Bone Joint Surg Am 2020;102:719-27. Crossref

8. Fortin P, Clarce A, Joseph L, Liang MH, Tanzer M, Ferland D, Phillips C, Partridge AJ, Bélisle P, Fossel AH, Mahomed $N$, Sledge CB, Katz JN. Outcomes of total hip and knee replacement: preoperative functional status predicts outcomes at six months after surgery. Arthritis Rheum 1999;42(8):1722-8. Crossref

9. Goesling J, Moser SE, Zaidi B, Hasset AL, Hilliard P, Hallstrom HB, Clauw DJ, Brummett CM. Trends and Predictors of Opioid Use Following Total Knee and Total Hip Arthroplasty. Pain 2016;157(6):1259-65. Crossref

10. Han C, LiX-D, Jiang H-Q, MaJ-X, MaX-L. The use of gabapentin in the management of postoperative pain after total knee arthroplasty. Medicine (Baltimore) 2016;95(23):e3883. Crossref

11. Olive DJ, Barrington MJ, Said SA, Kluger R. Randomised Controlled Trial Comparing Three Analgesia Regimens following Total Knee Joint Replacement: Continuous Femoral Nerve Block, Intrathecal Morphine or Both. Anaesth Intensive Care 2015;43(4):454-60. Crossref

12. Kovalak E, Doğan AT, Üzümcugil O, Obut A, Yıldız AS, Kanay E. Total diz artroplastisi sonrası erken dönemde gelişen ağrının kontrolünde periartiküler lokal infitrasyon analjezisi ile devamlı femoral sinir blokajının karşılaştırılması. Acta Orthop Traumatol Turc 2015;49(3):260-6. Crossref

13. Carli F, Clemente A, Asenjo JF, Kim DJ, Mistraletti G, Gomarasca M, Morabito A, Tanzer M. Analgesia and functional outcome aftertotal knee arthroplasty: periarticular infiltration vs continuous femoral nerve block. Br J Anaesth 2010;105:185-95. Crossref

14. Jiang X, Wang Q-Q, Wu C-A, Tian W. Analgesic Efficacy of Adductor Canal Block in Total Knee Arthroplasty: A Metaanalysis and Systematic Review. Orthop Surg 2016;8(3):294300. Crossref

15. Meftah M, Wong A, Nawabi DH. Pain Management After Total Knee Arthroplasty Using a Multimodal Approach. Orthopedics 2012;35(5):660-4. Crossref

16. Domenech J, Sanchis-Alfonso V, Espejo B. Changes in catastrophizing and kinesiophobia are predictive of changes in disability and pain after treatment in patients with anterior knee pain. Knee Surg Sports Traumatol Arthrosc 2014;22(10):2295-300. Crossref

17. Sharma R, Ardebili MA, Abdullah IN. Does Rehabilitation before Total Knee Arthroplasty Benefit Postoperative Recovery? A Systematic Review. Indian J Orthop 2019;53(1):138-47. Crossref
18. Demir H, Çalış M. Diz Artroplastisi Rehabilitasyonu. Erciyes Med J 2002;24(4):194-201. https://jag.journalagent.com/ erciyesmedj/pdfs/EMJ_24_4_194_201.pdf

19. Jones S, Alnaib M, Kokkinakis M, Wilkinson M, Gibson ASC, Kader D. Pre-operative patient education reduces length of stay after knee joint arthroplasty. Ann R Coll Surg Engl 2011;93(1):71-5. Crossref

20. Ekşioğlu E, Gürçay E. Total Diz Artroplastisi sonrası Rehabilitasyon. İst Tıp Fak Derg 2013;76(1):16-21. https:// dergipark.org.tr/tr/download/article-file/98870

21. Jahic D, Omeraovic D, Tanovic AT, Dzankovic F, Campara M. The Effect of Prehabilitation on Postoperative Outcome in Patients Following Primary Total Knee Arthroplasty. Med Arch 2018;72(6):439-43. Crossref

22. Akarcalı İ, Tuğay N, Erden Z, Tokgözoğlu M, Atilla B, Alpaslan M. Total diz artroplastili hastaların rehabilitasyonunda hızlandırılmış sürekli pasif hareket (CPM) protokolünün sonuçları. Hacettepe Ortop Derg 2001;11:20-3.

23. Lei Y-T, Xie J-W, Huang Q, Huang W, Pei F-X. Benefits of early ambulation within $24 \mathrm{~h}$ after total knee arthroplasty: a multicenter retrospective cohort study. Mil Med Res 2021;8(1):17. Crossref

24. Castrodad IMD, Recai TM, Abraham MM, Etcheson JI, Mohamed NS, Edalatpour A, Delanois RE. Rehabilitation protocols following total knee arthroplasty: a review of study designs and outcome measures. Ann Transl Med 2019;7(Suppl 7):S255. Crossref

25. Meier W, Mizner R, Marcus R, Dibble L, Peters C, Lastayo $P$. Total knee arthroplasty: Muscle impairments, functional limitations, and recommended rehabilitation approaches. J Orthop Sports Phys Ther 2008;38(5):246-56. Crossref

26. Liebs TR, Herzberg W, Rüther W, Haasters J, Russlies M, Hassenpflug J. Multicenter randomized controlled trial comparing early versus lateaquatic therapy after total hip or knee arthroplasty. Arch Phys Med Rehabil 2012;93(2):192-9. Crossref

27. Chughtai M, Kelly JJ, Newman JM, Sultan AA, Khlopas A, Sodhi N, Bhave A, Kolczun M, Mont M. The Role of Virtual Rehabilitation in Total and Unicompartmental Knee Arthroplasty. J Knee Surg 2019;32(1):105-10. Crossref

28. Klement MR, Rondon AJ, McEntee RM, Greenky MR, Austin MS. Web-Based, Self-Directed Physical Therapy After Total Knee Arthroplasty Is Safe and Effective for Most, but Not All, Patients. J Arthroplasty 2019;34(7S):S178-82. Crossref 